\title{
Towards "Improved Standards in the Science of Nutrition" through the Establishment of Federation of European Nutrition Societies Working Groups
}

\author{
Philip C. Calder ${ }^{a, b}$ Edith J.M. Feskens ${ }^{c}$ Aletta D. Kraneveld ${ }^{d}$ Jogchum Plat ${ }^{\mathrm{e}}$ \\ Pieter van 't Veer ${ }^{c}$ Jan de Vries ${ }^{f}$ \\ ${ }^{a}$ School of Human Development and Health, Faculty of Medicine, University of Southampton, Southampton, UK; ${ }^{\text {b NIHR }}$ \\ Southampton Biomedical Research Centre, University Hospital Southampton NHS Foundation Trust and University of

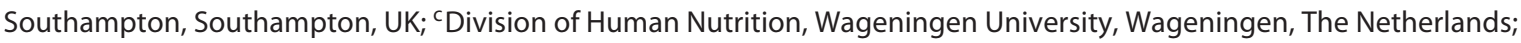 \\ dDivision of Pharmacology, Utrecht Institute for Pharmaceutical Sciences, Faculty of Science, Future Food Utrecht, \\ Utrecht University, Utrecht, The Netherlands; ${ }^{e}$ Department of Nutrition and Movement Sciences, School of Nutrition and \\ Translational Research in Metabolism, Maastricht University, Maastricht, The Netherlands; ${ }^{f}$ De Vries Nutrition Solutions, \\ Gorssel, The Netherlands
}

\section{Background}

In early 2015, the Dutch-based discussion group $\mathrm{Nu}-$ trition in Transition (NiT) initiated a critical evaluation of approaches used in nutrition science in order to understand challenges to the capability and credibility of the discipline and to foster discussions on how the standing of nutrition science can be improved [1]. Comparable initiatives in the United States [2,3], Australia [4] and elsewhere are working on increasing insights on how nutrition science can increase its credibility and capability, with each initiative taking its own approach. Discussion to date has identified that nutrition science is meeting inherent boundaries, hampering conceptual and methodological progress and the translation of novel insights into societal benefit and trust $[1,5]$. Nutrition science is facing limitations to its capability and credibility, impeding its societal value. New challenges lie in developing a sustainable, safe and healthy food system allowing future food security that supports optimal growth, development and function, gaining healthy life years, preventing multifactorial diseases and multi-morbidity, and designing feasible and effective personalized and public health nutrition strategies, contributing to meeting the sustainable development goals [6].

The relevance and impact of nutrition science primarily relate to the increased knowledge about the long-term impact of nutrients, foods and food patterns on health maintenance and disease onset. Methods in nutrition science need to adapt and expand to accommodate the new challenges. Reductionism is indispensable to answer questions related to specific nutrients and other food components. This approach has been highly successful for nutrition science for decades and has been the basis for current nutritional recommendations and for the positioning of single products through the use of nutrition and health claims. However, too much emphasis on "substances" (i.e., specific nutrients and non-nutrient components of foods) has become a dogma, hampering nutrition science's ability to diversify its views on individual and public health beyond the statistical or biochemical/physiological behaviour of single molecules. To investigate the effects of isolated substances and to demonstrate causality as required by the reductionist approach, the randomized controlled trial (RCT) is the highest ranked tool in the evidence pyramid. However, adequate nutrition is dependent on the karger@karger.com

(c) 2020 S. Karger AG, Basel

www.karger.com/anm

Karger"
Philip C. Calder

School of Human Development and Health, Faculty of Medicine University of Southampton, IDS Building, MP887 Southampton General Hospital Tremona Road, Southampton, SO16 6YD (UK)

E-Mail pcc@ soton.ac.uk 
complexity of foods and daily diets, sometimes including the use of dietary supplements and fortified foods, and on social, cultural and behavioural factors that influence food choice and consumption. Results of RCTs performed on single components, or even on single foods, often lead to conflicting views on what constitutes a healthy daily diet and hamper translation of nutrition science to the real world. To embrace the need for real-world solutions to complex challenges, new research methods and approaches beyond, but in addition to, RCTs need to be developed.

The general public is hugely interested in food matters and glean information through both traditional and social media outlets. In the meantime, the moral character and reliability of nutrition science and its champions often appear at stake, resulting in misinformation, confusion and loss of trust. This area of nutrition science communication needs addressing in order to better assure public and patient trust.

During its existence so far, the NiT discussion group has identified several main points of concern [1] that can be considered major areas for an open, honest and thorough debate and discussion, in order to catalyse a new global consensus on standards in the science of nutrition. Recently, the Federation of European Nutrition Societies (FENS) has chosen to further develop the NiT initiative and begin a more internationally oriented discussion on "Improving standards in the science of nutrition" [5]. It is now proposed to convene 3 working groups under the auspices of FENS, with each working group dealing with specific working areas: (1) the concepts and methodologies required to produce credible nutrition science in relation to public and personal health, (2) the organization, capabilities and funding structure required to produce credible nutrition science, (3) the way nutrition science is communicated to the general public and patients, to the medical community, and to industry.

\section{The Proposal for FENS Working Groups}

Three working groups are proposed (Fig. 1).

The first working group ("Concepts and methodologies") will focus on what concepts in nutrition science need revision and how this can be achieved, and what will be the consequences for methodologies in order to have credible and capable scientific research. Several questions have already been raised that most likely provide a basis for these discussions:

- What is health (maintenance) and how can it be made measurable?

Improved Standards in the Science of Nutrition

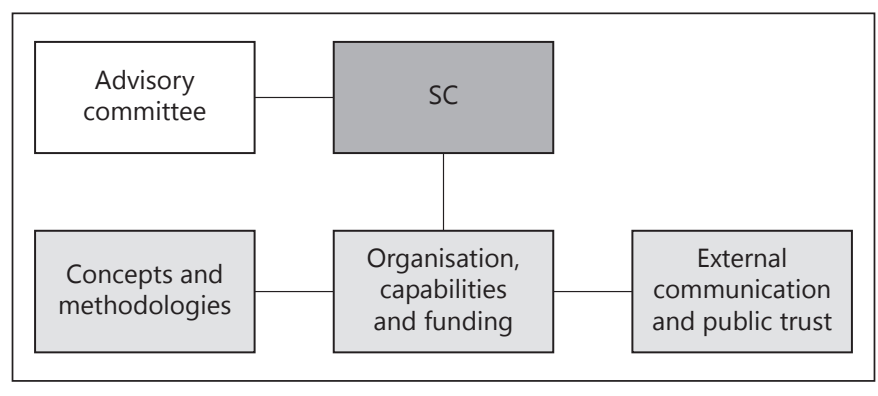

Fig. 1. Structure of the working groups. SC, steering committee.

- What are the requirements to establish a cause and effect relationship in the case of (primary and secondary) preventive effects of nutrition on health?

- Should and, if so, how can, the idea of "totality of evidence" be revised in the light of preventive effects of nutrition on health?

- What is needed to consider biomarkers and sets of biomarkers valid in that same context, and also how to distinguish between statistical validity and biological relevance, without losing rigor in science and without losing relevant scientific data?

- What is the role of real-life research and citizen/patient participation in future nutrition science?

The second working group ("Organisation, capabilities and funding”) will focus on:

- How research on nutrition and health is currently organized and funded in different countries and continents, including interactions among the various scientific disciplines;

- Whether that organization is optimal, and, if not, what structures, capabilities and interactions are required;

- How nutrition science is communicated "internally" (i.e., within the scientific world);

- How nutrition science can better recognise and deal with interactions with different stakeholders, including industry $[2,7]$.

The third working group ("External communication and public trust") will deal with the steps required to better assure "public trust" in nutrition science. "Public" includes those professionals that apply nutrition sciences in their daily practice as well as consumers and patients. As already indicated, the credibility of nutrition science is at stake with public confusion and distrust generated by conflicts and mixed messages. More honest communication of research findings and their meaning for the general public, medical professionals and patients is required, as well as better communication of risk and benefit. Of course this activity goes hand-in-hand with the

Ann Nutr Metab 2020;76:2-5

DOI: $10.1159 / 000506325$ 
Fig. 2. Timeline of the activities. WGs, working groups; SC, steering committee; FENS, Federation of European Nutrition Societies; IUNS, International Union of Nutritional Sciences; ASN, American Society of Nutrition.

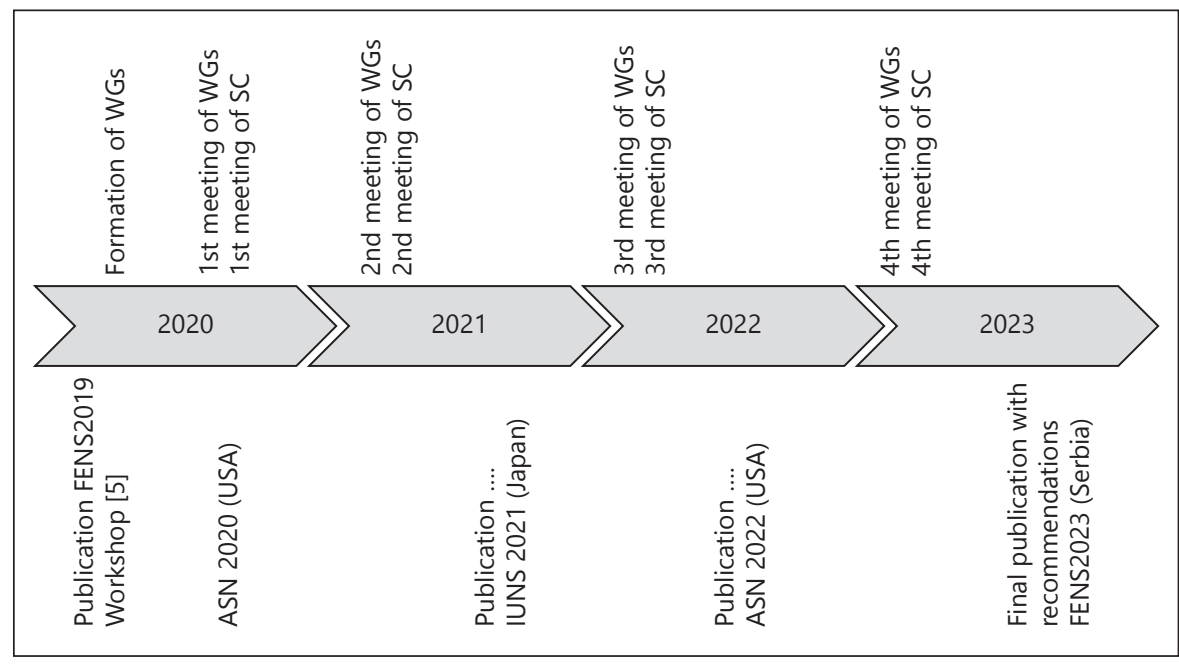

discussions in the other 2 working groups around credible and capable approaches and methodologies, internal communication, and the involvement of industry. Ways to discourage non-credible sources of information also need to be developed. The American Society of Nutrition has already conducted important work in analyzing the scientific rigour and credibility of the nutrition research landscape and what could be the best practices in nutrition science to earn and keep the public's trust [2, 3].

\section{The Structure of the Proposed Activity}

In addition to the 3 FENS working groups, there will be a Steering Group and an Advisory Committee (Fig. 1). The steering group will comprise of the President of FENS, the Chairs of the 3 working-groups and a Secretary. The steering group will be advised by an Advisory Committee that will comprise interested scientists from outside of Europe, for example, representing the American Society of Nutrition and the Nutrition Society of Australia, amongst others.

Each working group will have a Chair and a Secretary and up to 6 other members (to be appointed following a call in early 2020). For each working group, a set of criteria for eligibility for membership is defined:

- Background and interest in the main topic of the working group;

- Chair will be a senior academic researcher in the field of the topic.

Chair's responsibility will be to guarantee the progress of the tasks defined by the working group. The Secretary will be a more junior academic researcher with interest in the field of the topic and who is willing to spend a substantial amount of time in setting up relevant documents that are the basis of discussion meetings within the working group. The Secretary's responsibility will be to:

- Prepare and update the necessary documents for discussions in the working group and organise the (telcon and face-to-face) meetings;

- Write the minutes of meetings.

Members of the working groups will be, as far as possible, spread equally across European countries (and where possible with international contribution) and have a diverse distribution. Members' responsibilities will be to:

- Attend and actively contribute to the discussions of the working group;

- Review the documents that are the input for discussions;

- Support the Secretary with required (scientific) input on updating discussion documents.

Each working group will receive an initial briefing of activities. The briefing will be adapted according to the vision of the working group and foreseen activities of each working group must be achievable within the time frame of 3-3.5 years. Each year a 2-day face-to-face meeting will be organized to have a discussion within each working group (1 day) and between the working groups, the Steering Group, and the Advisory Committee (1 day). The output of each face-to-face meeting will be submitted as proceedings to a relevant journal. Output of the working groups will also be presented at international conferences and symposia where possible (e.g., American Society of Nutrition congresses in 2020 and 2022 and the International Union of Nutritional Sciences Conference in 2021). The frequency of digital meetings will be determined in close contact with the Chair and Secretary of the steering group.
Calder/Feskens/Kraneveld/Plat/ van 't Veer/de Vries 
It is aimed to complete the overall activity 6 months before the next FENS conference in Belgrade in 2023 (Fig. 2). It is anticipated that each working group will report its findings at that conference.

\section{Acknowledgments}

The work of the Foundation NiT is made possible by funding from the Universities of Groningen, Maastricht, Utrecht and Wageningen and from the Dutch Dairy Foundation, GoodMills and Unilever. P.C.C. has research funding from the Medical Research Council (MRC), the Biotechnology and Biological Sciences Research Council (BBSRC), the National Institute for Health Research (NIHR), the European Commission, BASF AS, Smartfish and Bayer Consumer Care; acts as an advisor/consultant to BASF AS, DSM, Cargill, Smartfish, Nutrileads, Bayer Consumer Care, Pfizer (now GSK) Consumer Healthcare and Friesland Campina; has received reimbursement for travel and/or speaking from $\mathrm{Da}$ none, Fresenius Kabi, Baxter, Pfizer (now GSK) Consumer Healthcare, Abbott, Smartfish, Biogredia and the California Walnut Commission; and is President and member of the Board of Directors of the European Branch of the International Life Sciences Institute. E.J.M.F. has received research funding from the Dutch Research Council (NWO), The Netherlands Organization for Health Research and Development (ZonMW), the Netherlands Heart Foundation, Diabetes Research Fund Netherlands, Netherlands Diabetes Federation, the European Commission, the Bill and Melinda Gates Foundation, the TopInstitute Food and Nutrition, the Dutch Topsector for Agriculture and Food (TKI-AF), Friesland Campina, and Knowledge Center Sugar and Health; has received reimbursement for travel and/or speaking from ILSI Europe and DSM; is Chair of the Scientific Advisory Board of the Joint Programme Initiative Healthy Diet for a Healthy Life (JPI-HDHL); and is Vice-Chair of the Board of the Foundation Nutrition in Transition (NiT). A.D.K. has research funding from the Dutch Lung Fund, the European Commission, the Dutch Topsector Life Sciences and Health (TKI-TSI), the Dutch Research Council (NWO), the Netherlands Organization for Health Research and Development (ZonMW); has public private partnerships with $\mathrm{Nu}$ tricia Research and the Netherlands Translational Research Center; has received reimbursement for travel and/or speaking from Nutricia Research, Johnson and Johnson and the International
Life Sciences Institute. J.P. has received research funding from the Dutch Research Council (NWO), The Netherlands Organization for Health Research and Development (ZonMW), Applied and Engineering Sciences (STW), the Dutch Topsector for Life Sciences and Health (TKI-LSH), the Californian Almond Foundation, EzCol, Newtricious, BASF, RAISIO, Upfield, and Unilever; has received reimbursement for travel and/or speaking from Unilever, Raisio, BASF, and Upfield; is secretary of the Board of the Foundation Nutrition in Transition (NiT); and is chair of the supervisory board from the foundation FIVES. P.V. has research funding from the Dutch Research Council (NWO), the Graduate School VLAG, the Dutch Topsector AgriFood (TKI-AF) and from Top Institute Food and Nutrition (TiFN) based on contributions from Unilever, DSM and the Dutch Dairy Association. He has received reimbursement for travel and/or speaking from WHO-Europe, PIT-actief and the Friesland Campina Institute; he chairs the board of the Food, Nutrition and Health Foundation. J.V. acts as a paid consultant to Evonik, Kellogg Europe, Kellogg USA, Tereos, Lefka O'Life, Danone, Special Nutrition Europe, Wageningen University, University Medical Centre Groningen, Healthgrain Forum and Nutrition Consultants Cooperative; is a board member of the Healthgrain Forum; partner of the Whole Grain Initiative (WGI); Chair of the working group Health Economics of the WGI; and member of the Public Affairs Commission of the Dutch Academy of Nutrition Sciences.

\section{Disclosure Statement}

The authors have no conflicts of interest to disclose.

\section{Funding Sources}

No funding was associated with this article.

\section{Author Contributions}

The content was conceived by P.C.C. and J.V. The initial text was drafted by J.V. All authors subsequently had equal input into the text and agree the final content.

\section{References}

1 Penders B, Wolters A, Feskens EF, Brouns F, Huber M, Maeckelberghe EL, et al. Capable and credible? Challenging nutrition science. Eur J Nutr. 2017 Sep;56(6):2009-12.

2 Kroeger CM, Garza C, Lynch CJ, Myers E, Rowe S, Schneeman BO, et al. Scientific rigor and credibility in the nutrition research landscape. Am J Clin Nutr. 2018 Mar;107(3):48494.

3 Garza C, Stover PJ, Ohlhorst SD, Field MS, Steinbrook R, Rowe S, et al. Best practices in nutrition science to earn and keep the public's trust. Am J Clin Nutr. 2019 Jan;109(1):22543.

4 Australian Academy of Science. Nourishing Australia: A decadal plan for the science of nutrition. 2019. Available from: https://www. science.org.au/files/userfiles/support/reports-and-plans/2019/2019-nutritiondecadal-plan.pdf.

5 Tufford AR, Calder PC, van't Veer P, Feskens EF, Ockhuizen T, Kraneveld A, et al. Is nutrition science fit for the 21st century? Moving towards transdisciplinary impacts in a chang- ing world. Manuscript in Preparation. Eur J Nutr. Forthcoming.

6 Willett W, Rockström J, Loken B, Springmann M, Lang T, Vermeulen S, et al. Food in the Anthropocene: the EAT-Lancet Commission on healthy diets from sustainable food systems. Lancet. 2019 Feb;393(10170):44792.

7 Uauy R. Academic-industry partnerships in addressing nutrition-[infection-immunityinflammation] interactions. Br J Nutr. 2007 Oct:98(Suppl 1):S17-23. 